\title{
ИНСТРУМЕНТЫ ЭКОНОМИЧЕСКОГО УПРАВЛЕНИЯ УСТОЙЧИВЫМ РАЗВИТИЕМ ПРЕДПРИЯТИЙ В УСЛОВИЯХ ЦИФРОВОЙ ТРАНСФОРМАЦИИ
}

\author{
(c) 2020 Смирнова Елена Викторовна \\ доктор экономических наук, профессор \\ Оренбургский государственный университет, Россия, Оренбург \\ E-mail: uadsev@mail.ru \\ (c) 2020 Цыганова Ирина Юрьевна \\ кандидат экономических наук, доцент \\ Оренбургский государственный университет, Россия, Оренбург \\ E-mail: iren23_83@mail.ru
}

Рассмотрены возможности устойчивого развития предприятий в условиях цифровой трансформации экономики. Делается вывод, что выбор и определение собственного пути развития в условиях цифровизации связаны с умением оценивать, контролировать и моделировать экономическую устойчивость, обеспечивать полное и эффективное использование внутренних факторов развития посредством применения инструментария экономического управления предприятиями. Утверждается, что улучшение качества принимаемых решений и их эффективная реализация достигается путем преодоления сложности проблемных ситуаций за счёт применения современных цифровых технологий во всех бизнес-процессах предприятия. В рамках данного исследования авторы предлагают инструменты, позволяющие управлять трансакционными издержками, которые рассматриваются как значимый фактор устойчивости рыночной позиции, способ достижения конкурентоспособности предприятий и наиболее подвержены изменениям в условиях цифровой трансформации экономики.

Ключевые слова: цифрровая трансформация, цифровая экономика, устойчивое развитие, экономическое управление предприятием, трансакционные издержки.

Утверждение в 2017 г. Правительством Российской Федерации программы «Цифровая экономика Российской Федерации» привело к формированию необходимых условий для осуществления национальной политики в сфере применения информационно-коммуникационных технологий (ИКТ), направленных на развитие всех секторов российской экономики и реализацию ее стратегических приоритетов.

В России объем использования цифровых технологий остается сравнительно небольшим. По данным Индикаторов цифровой экономики в 2018 г. индекс развития ИКТ в России составил 7,07 , что определяется 45 местом в международном рейтинге. При этом наибольший объем инвестиций в цифровые технологии приходится на коммерческие предприятия (1238 млрд. руб.), и их доля в общем объеме имеет тенденцию к росту [1].

Вместе с тем, цифровизация экономики уже оказала большое влияние на изменения в финансово-хозяйственной деятельности предприятий. Их необходимость была обусловлена следующими обстоятельствами:

1) чтобы работать эффективно, предприятиям приходится считаться с действиями конкурентов, а это предполагает ускорение изменений в товарах и услугах, взаимоотношениях с клиентами и поставщиками;

2) обновление ассортимента приводит к необходимости освоения новых технологий, повышающих эффективность производства, что в свою очередь сопровождается реструктуризацией технологических и бизнес-процессов;

3) поскольку жизненный цикл товаров и услуг постоянно сокращается, предприятия вынуждены увеличивать скорость изменений в своей деятельности;

4) глобализация экономики затрагивает институциональную среду, что вынуждает предприятия развивать способность к оперативной реакции на изменения в среде, поведении клиентов, работе подрядчиков и др.;

5) меняется подход к построению бизнеса со стороны инвесторов, так как он приобретает все более краткосрочный характер и сам ока- 
зывается технологией по созданию, развитию и ведению нового бизнеса на основе цифровых изменений [2].

Все эти обстоятельства свидетельствуют о том, что управление предприятиями является процессом постоянных изменений, и проблема устойчивого развития не только не потеряла своей актуальности, но и приобрела новую значимость.

Устойчивое развитие - это многомерный процесс, связанный с интеграцией в единое двух, на первый взгляд, противоречивых понятий «развитие» и «устойчивость» (развитие предполагает изменение определенного состояния субъекта, а устойчивость - его сохранение). Условием обладания устойчивостью к внешним воздействиям являются внутренние свойства самого объекта. Устойчивость - есть внешняя форма, внешнее проявление внутренней структуры объекта. Основа устойчивости заложена внутри самого объекта.

Устойчивое развитие в приложении к конкретному объекту - это многомерный, многоуровневый, разноплановый, многоэтапный процесс движения вперед, позволяющий достичь более высокого качественного состояния посредством количественных и качественных изменений (преобразований), характеризующихся закономерностью, цикличностью, единством, направленностью, непрерывностью, необратимостью, альтернативностью и многовариантностью, внутренней противоречивостью, взаимосвязью прогресса и регресса.

Выбор и определение собственного пути развития в условиях цифровизации связаны с умением предприятий оценивать, контролировать и моделировать собственную экономическую устойчивость, обеспечивая полное и эффективное использование внутренних факторов развития производства.

Цифровая трансформация нацелена на коренное изменение способов организации и ведения деятельности предприятий, целеориентированных на устойчивое развитие, за счет планируемого интенсивного внедрения цифровых технологий. По мнению экспертов, цифровая трансформация экономики России позволит увеличить валовой внутренний продукт (ВВП) к 2025 г. на 20-35\% или 4,5-9,0 трлн. руб., в Китае - на 22\%, в США на 1,6-2,2 трлн. долл. [3]

Эффективность устойчивого развития предприятий во многом будет зависеть от возмож- ности осуществления комплексного процесса реализации цифровых новаций, который должен быть основой организационных изменений, преобразующих цифровой процесс в корпоративный стандарт. Необходимо, чтобы управление предприятиями значительно упрощало деятельность по их мониторингу, выявлению «узких мест», разработке и воплощению эффективных управленческих решений с контролем негативно влияющих факторов [4].

В новых цифровых условиях актуальным становится понятие интерактивного поведения предприятия, позволяющего сделать его инициатором изменений на рынке на основе комплекса изменений в его финансово-хозяйственной деятельности с учетом, что она остается эффективной и будет таковой в долгосрочном периоде.

Цифровизация современного предприятия, лежащая в основе его устойчивого развития, не является одномоментной акцией. Это связано с тем, что действующая система управления формировалась в течении длительного периода времени и инерционна по своей сути. Кроме того, вызовы внешней среды, как стратегические изменения, одновременно создающие и возможности и угрозы (глобальная конкуренция; несоответствие экономической глобализации и политической разобщенности стран; введение экономических санкций со стороны ряда экономически сильных европейских стран и мировых держав; цифровизация экономики; пандемия короновируса и сопровождающая ее определенная изолированность национальных экономик) [5], не только осложняют ситуацию, но и требуют новых концептуальных подходов и инструментов управления экономикой.

Устойчивое развитие предприятий в условиях цифровой трансформации предполагает реализацию экономического управления через улучшение качества принимаемых решений и их эффективную реализацию путем преодоления сложности проблемных ситуаций, обусловленных большим количеством взаимодействующих факторов и причинно-следственных связей.

Как представляется, само понятие эффективного экономического управления предприятием - синоним его устойчивого развития. Экономическое управление предприятием позволяет обосновывать и принимать эффективные управленческие решения на основе предварительно выполненного анализа и планово-экономических расчетов [6]. Вся про- 
блема только в том, чтобы найти адекватные инструменты и технологии, а также выстроить механизм такого рода управления.

Основой экономического управления предприятием является использование методов: формирования информационного обеспечения; экономического анализа; прогнозирования; мониторинга; нормирования; планирования; экономического стимулирования; коммерческого расчета; ценообразования; идентификации и страхования рисков; контроля,-позволяющих экономически обосновывать решения, направленные на повышение эффективности финансово-хозяйственной деятельности. Отличительной чертой этих методов является возможность использования количественных измерений экономических процессов и явлений.

Формирование релевантного информационного обеспечения экономического управления предприятием напрямую связано с внедрением цифровых технологий во все бизнес-процессы предприятия. Предметом планирования и объектом приложения его методов являются ресурсы предприятия, а оптимизация их использования - цель планирования.

Привлечение и использование ресурсов на предприятии предполагает их трансформацию в производственные затраты, являющиеся одним из ключевых показателей эффективности деятельности. Для целей экономического управления эти затраты по способу отнесения на себестоимость продукции делятся на прямые и косвенные (общепроизводственные, общехозяйственные и коммерческие). При этом деление затрат специалисты производят самостоятельно, в зависимости от специфики деятельности предприятия, и фиксируют это в положениях его экономической политики.

Эффект цифрового развития экономики предприятий исследователи и эксперты во многом связывают с предполагаемым значительным сокращением трансакционных издержек, возникающих сверх производственных затрат и выражающих ценность разнообразных ресурсов (денег, времени, труда и т.п.), затраченных на осуществление экономического взаимодействия, а также качество порождающих их внешних и внутренних взаимосвязей [7]. Трансакционные издержки все чаще рассматриваются как важный фактор устойчивости рыночной позиции, способ достижения конкурентоспособности и базис инновационного развития предпри- ятий.

Впервые обратился к проблеме существования издержек рыночного механизма, которые он назвал трансакционными, и необходимости минимизации затрат на взаимодействие агентов на рынке Р. Коуз в работе «Природа фирмы» в 1937 г. [8]

В современной экономике использование новейших информационных технологий позволяет снизить переменные трансакционные издержки поиска информации, а также совокупные трансакционные издержки [9]. В связи с этим для целей экономического управления предприятиями целесообразно выделять из общей совокупности трансакционные издержки и объединять их в отдельную группу, что зачастую на практике является проблематичным.

Наиболее приемлемым представляется выделение трансакционных издержек в следующих разрезах:

- по центрам ответственности;

- по рыночным сегментам;

- по предприятию в целом.

Помимо оценки влияния цифровизации экономики на трансакционные издержки, возможной представляется оценка потенциала дальнейшего снижения трансакционных издержек под влиянием расширения использования цифровых технологий, что определяет актуальность реализации расчета себестоимости с учетом трансакционных издержек и формирования их плановой сметы для целей экономического управления устойчивым развитием в условиях цифровой трансформации.

Такой подход делает возможным определение себестоимости продукции как с помощью традиционного метода расчета полных затрат, так и метода расчета ограниченной себестоимости с выделением трансакционных издержек. При этом необходимо осуществить поэлементную декомпозицию издержек с помощью качественного анализа каждого из составляющих их элементов с тем, чтобы по качественным признакам отнести те или иные издержки к разряду трансформационных (производственных) или трансакционных.

Эффективным можно считать такое экономическое управление трансакционными издержками, которое базируется на приемлемой для конкретного предприятия их классификации и возможности полного анализа, отнесении трансакционных издержек на соответствующие 
подразделения, что связано с установлением личной ответственности, прогнозированием и планированием трансакционных издержек, составлением сметы на плановый период. Это позволит в процессе анализа выявлять трансакционные издержки, не давшие положительного результата, лица и подразделения, ответственные за них.

Мониторинг деятельности предприятия с использованием сметной группировки трансакционных издержек приводит к обоснованию экономической необходимости принимаемых управленческих решений по изменениям в институциональной структуре. Кроме того, в процессе составления целевых смет расходов предприятия, по нашему мнению, необходимо учитывать трансакционные издержки с целью их минимизации. Такой подход необходим на завершающей стадии разработки разделов тактического плана предприятия. Он позволяет сбалансировать затраты предприятия и его подразделений и тем самым контролировать правильность всех планово-экономических расчетов, укрепить экономическую базу коммерческого расчета. Предлагаемый авторами формат сводной плановой сметы трансакционных издержек предприятия представлен в таблице 1.

Анализ отклонений выполнения сметы трансакционных издержек производится с целью контроля за расходованием средств, выявления резервов их снижения. Важные сведения при анализе сметы трансакционных издержек могут быть получены также путем изучения динамики анализируемых издержек за ряд периодов. По этим данным устанавливаются абсолютные и относительные изменения отдельных видов трансакционных издержек.

Анализ сводной сметы трансакционных издержек предприятия позволит предложить мероприятия по их оптимизации с учетом современных тенденций цифровизации экономики РФ.

Формирование и анализ сметы трансакционных издержек способствуют снижению неопределенности в деятельности предприятий, так как позволяют формировать информацию о его вероятных будущих транзакциях с учетом цифровых факторов развития экономики.

Реализация метода планового расчета ограниченной себестоимости с выделением трансакционных издержек связана с тем, что в состав затрат себестоимости реализованной продукции включаются переменные прямые затраты и переменные трансакционные издержки - издержки, величина которых зависит от количества сделок или их объема (совершаются по каждой транзакции отдельно, например, издержки на подготовку и реализацию конкретного контракта). Косвенные расходы и постоянные трансакционные издержки - издержки, величина которых не зависит от количества сделок или их объема (совершаются один раз для некоторого количества транзакций, например, издержки по установлению и защите прав собственности) включаются в состав затрат полной себестоимости продукции предприятия.

Порядок определения полной себестоимости продукции на примере конкретного предприятия при реализации метода расчета полных затрат и метода расчета ограниченной себестоимости с выделением трансакционных издержек представлен в таблице 2 .

Совокупность приведенных выше положений позволяет установить последовательность действий, связанных с оценкой влияния трансакционных издержек на полную себестоимость продукции предприятия (рисунок 1).

Реализация эффективного экономического управления трансакционными издержками минимизирует их, и снижает негативное воздействие на результаты деятельности предприятий, увеличивая выгоды от взаимодействия участников рынка [10], и позволит:

- обеспечить экономической информацией с высокой степенью детализации процесс принятия управленческих решений;

- осуществлять контроль экономической эффективности деятельности предприятий и минимизировать эти издержки;

- выявлять резервы роста в области экономического управления устойчивым развитием предприятий.

Таким образом, экономическое управление устойчивым развитием предприятий является необходимым условием повышения их конкурентоспособности, и требует разработки инструментария, соответствующего цифровым преобразованиям в российской экономике. Это позволит максимизировать эффективность финансово-хозяйственной деятельности, адаптировав ее и систему управления предприятиями к внедрению современных информационно-коммуникационных технологий. 
Таблица 1. Примерный формат сводной плановой сметы трансакционных издержек предприятия *

\begin{tabular}{|c|c|c|c|c|c|c|}
\hline \multirow{2}{*}{\multicolumn{2}{|c|}{$\begin{array}{l}\text { Наименование организации: } \mathrm{AO} \text { «XX» } \\
\text { Структурное подразделение: } \mathrm{xxx}\end{array}$}} & \multirow{3}{*}{\multicolumn{5}{|c|}{$\begin{array}{l}\text { Утверждаю: } \\
\text { Должность подпись расшифровка подписи дата }\end{array}$}} \\
\hline & & & & & & \\
\hline \multicolumn{2}{|c|}{ Ед. изм.: тыс. руб. } & & & & & \\
\hline \multicolumn{7}{|c|}{ Смета трансакционных издержек $\mathrm{OOO}$ «XXX» на 2021 г. } \\
\hline \multicolumn{2}{|l|}{ Номер документа: № xxx } & \multicolumn{5}{|c|}{ Дата составления: XX/XX/2020 г. } \\
\hline \multirow{3}{*}{ Статьи затрат } & \multirow{3}{*}{$\begin{array}{l}\text { Отчетные } \\
\text { данные } \\
\text { базисного } \\
\text { периода }\end{array}$} & \multicolumn{5}{|c|}{ На планируемый период } \\
\hline & & \multirow{2}{*}{ всего } & \multicolumn{4}{|c|}{ в том числе по кварталам } \\
\hline & & & I & II & III & IV \\
\hline $\begin{array}{l}\text { 1. Информационные издержки } \\
\text { (консультационные, посредниче- } \\
\text { ские услуги) }\end{array}$ & 12345 & 10673 & 2670 & 3455 & 3219 & 1326 \\
\hline $\begin{array}{l}\text { 2. Издержки ведения переговоров } \\
\text { и заключения договоров, в т.ч. } \\
\text { командировочные и представи- } \\
\text { тельские расходы } \\
\end{array}$ & 6789 & 7231 & 3200 & 1288 & 1560 & 1183 \\
\hline $\begin{array}{l}\text { 3. Издержки измерения (проверка } \\
\text { качества продукции, стандартиза- } \\
\text { ция, маркировка, сертификация) }\end{array}$ & 1234 & 2990 & 789 & 545 & 456 & 1200 \\
\hline $\begin{array}{l}\text { 4. Издержки координации (из- } \\
\text { держки связи внутри предприя- } \\
\text { тия) }\end{array}$ & 656 & 584 & 146 & 146 & 146 & 146 \\
\hline $\begin{array}{l}\text { 5. Издержки спецификации и } \\
\text { защиты прав собственности } \\
\text { (затраты на услуги юристов, } \\
\text { аудиторов, охранных служб, } \\
\text { судебные расходы, оплата услуг } \\
\text { государственных органов, затраты } \\
\text { времени и ресурсов, необходимых } \\
\text { для восстановления нарушенных } \\
\text { прав, получение патентов на } \\
\text { изобретения, лицензирование, } \\
\text { аккредитация) }\end{array}$ & 45670 & 32872 & 7790 & 8456 & 9733 & 6893 \\
\hline $\begin{array}{l}\text { 6. Издержки оппортунистического } \\
\text { поведения (неустойки (штрафы, } \\
\text { пени) за ненадлежащее выполне- } \\
\text { ние договоров) }\end{array}$ & - & - & - & - & - & - \\
\hline 7. Транспортные расходы & 23457 & 19630 & 4001 & 3467 & 5890 & 6272 \\
\hline 8. Налоги & 3890 & 4678 & 1169,5 & 1169,5 & 1169,5 & 1169,5 \\
\hline 9. Издержки по подбору персонала & 890 & 1730 & 531 & 489 & 342 & 368 \\
\hline Итого & 94931 & 80388 & 20296,5 & 19015,5 & 22515,5 & 18557,5 \\
\hline \multicolumn{7}{|c|}{$\begin{array}{l}\text { Исполнитель: } \\
\text { Должность подпись расшифровка подписи дата }\end{array}$} \\
\hline \multicolumn{7}{|c|}{$\begin{array}{l}\text { Примечание (особые отметки): количество договоров, план (график) повышения квалификации персонала и } \\
\text { т.п. }\end{array}$} \\
\hline
\end{tabular}


Таблица 2. Порядок определения полной себестоимости продукции при реализации методов планового расчета полных затрат и ограниченной себестоимости с выделением трансакционных издержек *

\begin{tabular}{|c|c|c|c|}
\hline \multicolumn{2}{|c|}{ Метод расчета полных затрат } & \multicolumn{2}{|c|}{$\begin{array}{c}\text { Метод расчета ограниченной себестоимости с выде- } \\
\text { лением трансакционных издержек }\end{array}$} \\
\hline Показатель & $\begin{array}{l}\text { Сумма затрат, } \\
\text { тыс. руб. }\end{array}$ & Показатель & $\begin{array}{l}\text { Сумма затрат, } \\
\text { тыс. руб. }\end{array}$ \\
\hline Выручка & 19220 & Выручка & 19220 \\
\hline Прямые материальные затратын** & 5456 & Прямые материальные затраты*** & 5456 \\
\hline Прямые трудовые затратын* & 1984 & Прямые трудовые затраты*** & 1984 \\
\hline Общепроизводственные расходы** & 5208 & $\begin{array}{l}\text { Переменные трансакционные } \\
\text { издержки }\end{array}$ & 696 \\
\hline Валовая прибыль & 6572 & Валовая прибыль & 11084 \\
\hline Коммерческие расходы** & 5208 & $\begin{array}{l}\text { Общепроизводственные, обще- } \\
\text { хозяйственные и коммерческие } \\
\text { расходы** }\end{array}$ & 8200 \\
\hline Общехозяйственные расходы** & - & $\begin{array}{l}\text { Постоянные трансакционные } \\
\text { издержки }\end{array}$ & 1520 \\
\hline Прибыль от продаж & 1364 & Прибыль от продаж & 1364 \\
\hline \multicolumn{4}{|c|}{$\begin{array}{l}\text { * Составлено авторами на основе данных бухгалтерского и оперативного учета за } 9 \text { месяцев } 2020 \text { года и } \\
\text { прогнозных оценок, полученных по результатам экспертного опроса персонала, планируемых на } 2021 \text { год } \\
\text { транзакциях одного из промышленных предприятий Оренбургской области } \\
\text { ** Трансформационные (производственные) издержки }\end{array}$} \\
\hline
\end{tabular}

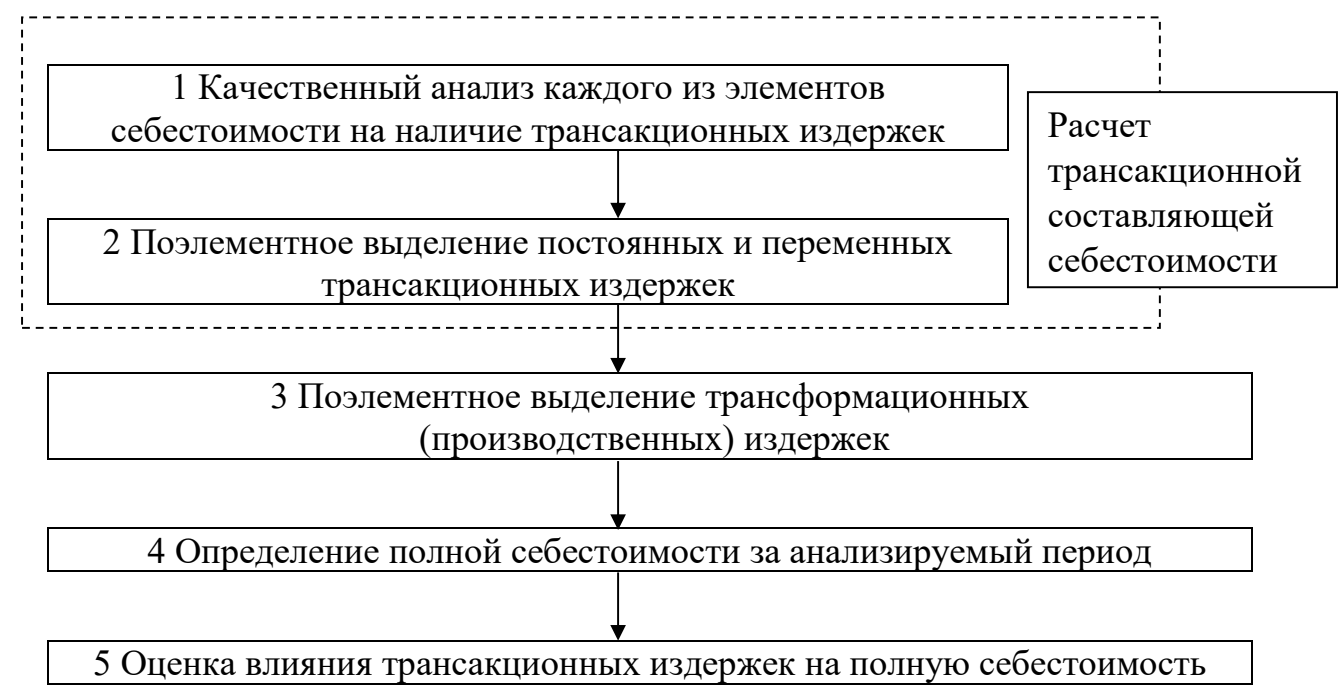

Рисунок 1. Последовательность действий, связанных с оценкой влияния трансакционных издержек на полную себестоимость продукции предприятия 


\section{Библиографический список}

1. Цифровая экономика: 2019: краткий статистический сборник / Г.И.Абдрахманова, К.О.Вишневский, Л. М. Гохберг и др.; Нац. ис-след. ун-т «Высшая школа экономики».- М.: НИУ ВШЭ, 2019._-96 с.-ISBN $978-$ 5-7598-1927-1.

2. Мирошниченко, А. Системы непрерывного совершенствования деятельности предприятий на основе менеджмента знаний / А. Мирошниченко // НАУКА И ИННОВАЦИИ. - 2014. - № 2 (132). Февраль. - С. 55-60.

3. Колодняя, Г. Цифровая экономика: особенности развития в России / Г. Колодняя // Экономист.- 2018.№ 4.- С.63-69.

4. Смирнова, E. В. Некоторые положения экономического управления устойчивым развитием промышленных предприятий в условиях реиндустриализации / Е. В. Смирнова, Н.А. Тычинина, И. Ю.Цыганова, О. В.Федорищева // Экономические науки.-2019.- Т. 12 (181). - С. 324-331.

5. Гуськова, Н.Д. Современный подход к процессу непрерывного совершенствования и развития российских предприятий / Н.Д. Гуськова, А. В.Ерастова, В.П.Ерастова // Экономические и социально-гуманитарные исследования. - 2019. - № 4 (24). - С. 6-12.

6. Смирнова, E.В.Экономическое управление сегментами бизнеса промышленных предприятий / Е. В. Смирнова, И. Ю. Цыганова // Экономические науки. - 2018. - № 12 (169). - С. 22-29.

7. Манукян, М. М. Трансакционные издержки: сущность и динамика в российской экономике / М. М. Манукян, Л.В.Борзых // Вестник Самарского государственного университета. Серия: Экономика и управление.2014. - № 8 (119). - C. 71-74.

8. Coase, R. H. The Nature of the Firm / R. H. Coase // Economica. - 1937.- Vol. 4. - № 16. November.

9. Институциональная экономика: новая институциональная экономическая теория: учебник / Мгу им. М. В. Ломоносова; Под общ.ред. А. А. Аузана. - 2 изд.- Москва: ИНФРА-М, 2011. - 447с. - (Учеб.эконом. факта МГУ им. М.В.Ломоносова).- ISBN 978-5-16-004387-6. - Текст: электронный.- URL: https://znanium. com/catalog/product/248615 (дата обращения: 20.11.2020).- Режим доступа: по подписке.

10. Аузан, А.А.Цифровая экономика как экономика: институциональные тренды / А.А. Аузан // Вестник Московского университета. Серия 6. Экономика. - 2019. - № 6.- С. 12-19. 